Judit Blair

\title{
De-Demonising the Old Testament
}

\author{
An Investigation of Azazel, Lilith, Deber, Qeteb and Reshef in the Hebrew Bible
}

[Die Entdämonisierung des Alten Testaments. Eine Untersuchung von Azazel, Lilith, Deber, Qeteb und Reshef in der Hebräischen Bibel.]

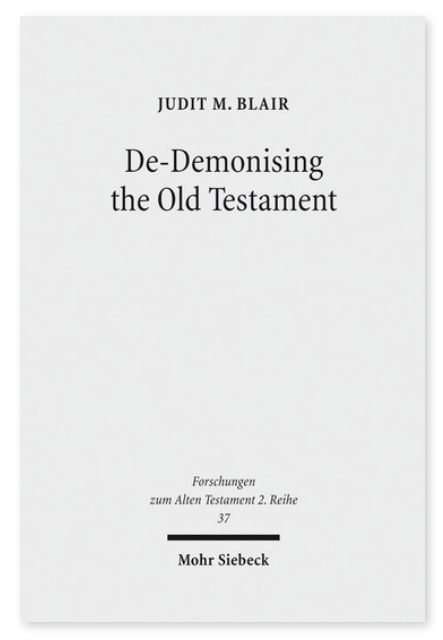

2009. XVI, 266 Seiten. FAT II 37

ISBN 978-3-16-151135-6

DOI 10.1628/978-3-16-151135-6

eBook PDF 74,00€

ISBN 978-3-16-150131-9

fadengeheftete Broschur 74,00€
Veröffentlicht auf Englisch.

Judit M. Blair hinterfragt die weit verbreitete Auffassung, daß in der Hebräischen Bibel Azazel, Lilith, Deber, Qeteb und Reshef für Namen von Dämonen stehen. Sie behauptet, bedeutende Werke über dieses Thema gingen von der Annahme aus, daß diese Namen im antiken Nahen Osten sowie auch später dämonisch belegt waren oder Gottheiten zugeschrieben waren, die dann von den Autoren der Hebräischen Bibel dämonisiert wurden. Ohne den Wahrheitsgehalt traditioneller Methoden zu hinterfragen, ergänzt die Autorin die bestehenden Werke, indem sie eine Exegese anhand einer genauen Lektüre aller relevanten Texte der hebräischen Bibel unternimmt, in der diese 5 Begriffe auftauchen. Dabei berücksichtigt sie insbesondere die linguistischen, semantischen und strukturellen Ebenen der Texte. Einen Schwerpunkt legt sie auf die genaue

Untersuchung des direkten Kontexts, um die Funktion jeden Begriffs zu bestimmen. Sie bemerkt verschiedene Zeichen in den Texten, vornehmlich den Gebrauch vieler poetischer/rhetorischer Kunstgriffe: Personifizierung, Parallelismus, Verwendung von Gleichnissen, Ironie und mythologischen Elementen.

Judit Blair Born 1966; 2008 PhD at the University of Edinburgh; presently involved with independent research.

Jetzt bestellen:

https://mohrsiebeck.com/buch/de-demonising-the-old-testament-9783161511356?no_cache=1

order@mohrsiebeck.com

Telefon: +49 (0)7071-923-17

Telefax: $+49(0) 7071-51104$ 